\title{
PRESCHOOL CHILDREN DEVELOPMENT EMPATHY THROUGT INDIVIDUALIZED MATERIALS
}

\author{
Agneta Simeonsdotter Svensson \\ University of Gothenburg, Sweden \\ E-mail: agneta.simeonsdotter@ped.gu.se
}

\begin{abstract}
The overall objective of the study is to investigate whether the understanding of animals and their living conditions is a way for child's emphatic ability. One interesting question is in what way children show that they are developing empathy. Do children show some change in the way they talk about animals and their living conditions? How is this change revealed? The theoretical basis of this study is based on Martin Hoffman's research (2000) which emphasizes the importance of learning and of encouraging empathy in children. The study design is qualitative and was conducted using conversations with child participants, notes, photographs and video recordings of the children working with the teaching material "cat picture" and dog picture". The participants comprised of 52 children aged between 3-5 years, divided into a main group and a control group with 26 children, 12 girls and 14 boys in each group. The results show that there is a difference in the two testing occasions between the main group and the control group. As the main group were given opportunities to think and reflect and work with the material, ideas about thoughts on ethical issues could emerge and developed further. Sustainable development must begin with the children. This is the best investment that any society can make.
\end{abstract}

Key words: animals, empathy, ethics, preschool children.

\section{Introduction}

There are many reasons for considering using animals in educational work with children in kindergarten. Children and animals can easily enter into close and trusting relationships that could result in positive effects on child development, including the strengthening of selfesteem, a greater ability to take responsibility and a feeling of better self-control. Animals stimulate being present in the moment, provide love and security without words as that can be misunderstood or forgotten. Animals often have a decisive impact on a child that can sometimes be greater than the influence of parents and other people (Melson, 2001). Several international studies show that children, who have a close relationship with an animal in the home or come into contact with animals in a sympathetic way in school, develop greater empathy for both animals and humans (Myers, 1998; Poresky, 1990; Vizek-Vidovic, Stetic \& Bratko, 1999).

This study is based on a collaborative project year 2012 with an animal protection association in Sweden (Animal Welfare Sweden). Teaching materials for use in preschool with animal pictures and additional exercises are examined.

The teaching materials have a scientific basis (Hoffman, 2000) and were prepared by Kerstin Malm, PhD in ethology and Day Einarsson, educationalist. This is the first scientific based study that tests the material. Because the material is new, it has not previously been used in preschools. The idea is that when the children use the teaching material they are coached to take the perspectives of others and to understand their own role in a situation. Through targeted conversations and exercises based on the animal pictures, children in kindergarten can practice their empathy and develop the ability to express themselves and take a position on issues in life. 
Agneta SIMEONSDOTTER SVENSSON. Preschool Children Development Empathy througt Individualized Materials

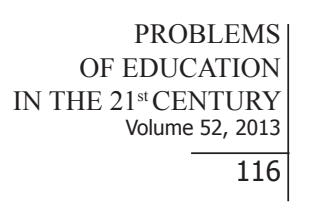

PROBLEMS

$21^{\mathrm{st}}$ CENTURY

Volume $\frac{52,2013}{116}$

\section{Problem of Research}

Being able to see someone else's perspective is the basis for an empathetic and respectful behavior and a higher moral reasoning. The relationships between showing care, to know the different forms of empathy and have a good sense of justice is strong. That way the ability to put oneself in someone else's situation is a very important part of empathy, care and matters of right and wrong. The relationships between caring, know various forms of empathy and to have a good sense of justice are strong. Taking perspective provides a higher degree of care and thoughts of caring. It also leads to the highest stage of reflecting independently around morality of fairness, where higher moral values are pursued. In children and young people one have found a correlation between the ability to take a perspective, to feel sympathy and pro-social reasoning. To train and encourage young people's moral development, the ability to take a perspective is together with reflection very effective (Juujärvi, Myyryb \& Pesso, 2010).

Empathy is not only a word but also a disputed concept. Empathy, according to Gallie (1956) is synonymous with "immersion, intensive understanding, commitment and compassion", illustrating that words can have different meanings, different conceptual content, for their interpreters. In this study empathy is interpreted mean affinity and understanding for people, animals, nature, and their living conditions. The links between showing on cares and experiencing different forms of empathy and having a good sense of Justice are strong, according to Damon (1984) and Juujarvi, Myyryb and Pesso (2010). A US report (Ascion, 2001) discusses how children become violent toward animals. Children's violence against towards animals needs attention because is a warning signal. An article by Dadd's (2002) noted that a training programme a focusing on the child's relationship to animals had an effect on children's ability to empathize with both animals and humans. The current study stresses the importance of teaching children about empathy as early as in kindergarten. In view of the importance of early intervention, the overall objective of the study is to investigate whether the understanding of animals and their living conditions is a way for child's emphatic ability. One interesting question is how children show that they have developed empathy. Is there some change in the way they talk about animals and their living conditions? How is this change manifested?

\section{Research Focus}

The theoretical basis for this study is Martin Hoffman's research (2000). In his classic work "Empathy and Moral Development" he points out the meaning for learning and the importance of stimulating empathy in children. Social learning is needed to trigger and enhance empathy and the pro-social emotions that it gives rise to. The compassion and care that most people feel for their family and close friends need, according to Hoffman, systematically trained to include others in the vicinity, those not known and ultimately everyone at any time. But in highly individualistic societies and communities where competition and contending are set as the target, the will to help others is usually weakened.

One important task in moral teaching is to overcome the partial in the strong empathy that many feel for their loved ones according to Hoffman (2000). In addition to needing the right conditions in order to develop the ability to empathize can be limited by other circumstances. Growing up under authoritarian conditions constitutes the biggest risk to not development an empathetic moral norm (Hoffman, 2000). The development of empathy is associated with how moral thinking matures in young people (Damon, 1984). Empathy therefore needs to be trained, together with the identification of the self. That these two are developed in parallel would mean that they are both necessary for the capacity of moral reasoning. In order to provide children and young people's self and empathy to grow side by side, we should give them the possibility of identification of self and empathy in all four stages. How quickly we develop through these 
steps is individual and we must be encouraged at all levels in order to be able to go through the steps in the most complete and individually suited way possible. We then get individuals who

are well equipped for moral thinking and can detect and reveal thoughts and thinking systems that do not correlate to an empathic moral norm (Demon, 1984).

\section{Methodology of Research}

\section{Sample of Research}

The participants in the study comprised 52 children aged 3-5 years, divided into a main group and a control group of 26 children, with 12 girls and 14 boys in each. The 52 children attend four kindergartens in four different neighbourhoods in a city in Sweden. In designing the study, the aim was to get a spread of preschools representing children from different neighbourhoods and backgrounds. The preschools are given the fictitious names, Hedgehog, Crab, Chaffinch and Lion. In the study breakdown of the number children participating are as follows: Hedgehog, 16 children ( 8 in the main/ 8 in control group), Crab, 14 children (7 in the main / 7 in the control group), Chaffinch, 12 children (6 in the main / 6 in control group) and Lion, 10 children ( 5 in the main / 5 in the control group).

\section{Instrument and Procedures}

The study is qualitative in nature and was conducted through conversations with the children, notes, photographs and video recordings of the children's work with the teaching material "Cat Picture" and Dog Picture ". The introductory and final conversations were conducted by the author of this article, based on the children's perspective (Pramling Samuelsson \& Asplund Carlsson, 2008; Sommer, Pramling Samuelsson \& Hundeide, 2010). Visits were made to four different preschools, two different occasions for the main group and one occasion for the control, per preschool. On the first occasion the exercises were introduced to the children in the main group. On the second occasion the exercises were followed up and the children and preschool teacher in the main group were questioned about the content, to see if they showed that they had developed the capacity for empathy and, if so, has this was manifested. The second visit took place about two months after the first time. On the second occasion the children in the control group were also asked questions in order to find out how they talked about ethical issues using the material as background (Mishler, 1986). The main group had been working on ethical issues in connection with the exercises which the control group had not. Between visits 1 and 2 the teachers worked with the children who had been introduced to the exercises (the main group). They worked with the exercises two days a week over a two month period by following the instructions from the introduction. The preschool teachers wrote notes and they used a video camera to record at each exercise to document the children's progress. These notes were the basis for the analyses

The study was designed to have access to a spread of preschools representing children from different neighbourhoods and backgrounds, not to show the similarities or differences due to socioeconomic backgrounds, but to obtain as a representative sample as possible.

Preschools in various districts were contacted by telephone. Four kindergartens were chosen based on the principle that the children come from several districts. Information letter to educators and parents were handed over on an initial visit. The parental information letter contained an information letter which had to be completed if the parent gave permission for the child to participate in the study. The Swedish Research Council's research ethics (www.vr.se) regarding information requirements, consent requirements, confidentiality and use of results have been adhered to in this study. This means that all those who participated in the study will remain anonymous and have been assigned fictitious names. 
PROBLEMS

OF EDUCATION

IN THE $21^{\text {st }}$ CENTURY

Volume 52,2013

118

\section{Data Analysis}

The qualitative approach was inspired by phenomenographic analysis where the focus is on identifying qualitatively different ways of experiencing a phenomenon (Pramling Samuelsson \& Asplund Carlsson, 2008; Simeonsdotter Svensson, 2009). In this study, this meant trying to understand what capacity the children have for empathy and compassion for both animals and has they show or express it. When processing the data all, 52 children's expressions, narratives, talk and body language have been analysed.

Interviews with the children and child-to-child conversations, own and preschool teacher's notes, photographs and video recordings formed the basis of the analysis and interpretation process. The two occasions with the main group were analysed separately and together, as well as the occasions with the control group.

The interpretation process in a phenomenographic analysis can be considered as a chain of interpretations based on the whole and the parts and whole (Marton, Beaty \& Dall'Alba, 1993; Marton \& Pong, 2005). Interpretation of whole and part are linked mostly by hermeneutics and the hermeneutic spiral (Gadamer, 1999). Part and whole must be related to each other in a reasonable manner in order to be credible, which can also be related to how phenomenographic inspired analysis is used in this study. The interpretation from the entirety to the parts was conducted in order to increase understanding of the collected data. Interpretation and understanding of the process involves an understanding of the context, the whole increases, which also changes the understanding of the individual parts. Notes from the preschool teachers were analyzed according to their experience of the exercises with the children in terms of accessibility, relevant content for learning and child's interest. Representative quotes of statements by the children supported the meaning of the conversations.

\section{Results of Research}

The results present quote from ethical conversations with the children about the two animal images, a cat and a dog. The educational material should primarily be seen in a Swedish context, the Swedish preschool with a link to the preschool curriculum (Pramling Samuelsson, Sommer \& Hundeide in print) but can also, of course, be seen in an international context.

When educators in preschool use teaching materials they become an instrument in the work of following the curriculum. Working with these exercises, gives the children the opportunity to strengthen their capacity for empathy and compassion with both animals and humans. This can be done in a variety of ways, but should start from the children's interest in a learning situation (Pramling Samuelsson \& Johansson, 2006; Pramling Samuelsson \& Asplund Carlsson, 2008).

Examples of the children think and say about the ethical dilemmas are presented using quotations from the conversations about the images. The exercise is called "How does the animal feel? - How do I feel"? The results of the analysis present some examples from all four preschools taken from the main group introduction and final times. The statements represent the results of the study and are a representative sample. The control group's results are highlighted in the discussion and discussed in relation to the main group's performance.

\section{Exercise - How does the animal feel - How do I feel?}

In this exercise, the children from the four kindergartens (Hedgehog, Crab, Chaffinch and Lion) sit in a circle on the floor. The children look at and talk about the images of a cat and a $\mathrm{dog}$, which lie on a mat on the floor. Introductory exercises were conducted with the main group in April 2012 and the final exercises with the main group and the only period with the control group look place in June 2012. 


\section{Cat Picture}

The first picture is of a cat which was the subject of the conversation with the children. What do you think the cat wants to tell us? Is it afraid? Or is it perhaps a bit curious or does it wants to tell us something? Children from Hedgehog and Crab participate in this exercise. Four children in the main group, Alva, Hjalmar, Vera and Johan and four in the control group Sara, Simon, Ida and Ivar are used to present the responses to the exercise.

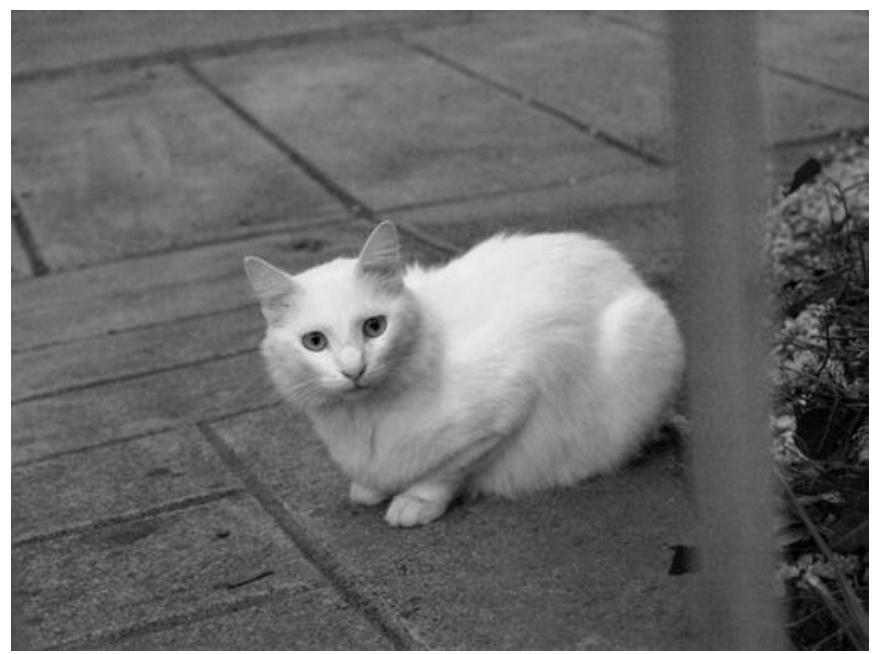

\section{Figure 1: Cat outdoor. Illustrations by Kerstin Malm.}

\section{The Main Group}

Occasion 1

Talks on the picture cat of based on the issues raised in the questions above. Examples of the statements of the four children in the main group:

1. The cat is lonely ... he can't find his home ... because there is no one at his home (Alva at Hedgehog).

2. He can't find his way home ... perhaps he looks ill ... (Hjalmar at Crab).

3. She looks happy ... is it a guy? It's probably a girl ... She is white and sweet ... (Vera at Hedgehog).

4. I don't know... think he's afraid of thunder he looks up (Johan at Crab).

Occasion 2

On the next occasion the questions and conversation about the cat picture were repeated. Below are the responses of four children:

1. Everyone is at work and he is alone and a bit scared of ghosts. I'm always curious if there are ghosts. You have to check ... and help the cat get away so he does not get 
Agneta SIMEONSDOTTER SVENSSON. Preschool Children Development Empathy througt Individualized Materials

PROBLEMS

OF EDUCATION

IN THE $21^{\text {st }}$ CENTURY Volume 52, 2013

120

scared. Then my mom and sister come and we can play and everything is fine (Alva at Hedgehog).

2. My grandmother had a cat that was blind. But I usually carry him so he does not hurt himself. Otto (comrade) always ... I give him a plaster then ... (Hjalmar at Crab).

3. I think she might jump up on the balcony and is afraid of falling off... done it before, I think. Oh, oh, oh, we have to save it so it doesn't hurt itself ... is so cute. Be careful of falling off the balcony ... dangerous ... (Vera at Hedgehog).

4. He's probably scared ... look ... he looks. Is it thunder or what? He can follow with me in the basement. Then he will not be afraid ...how sad. Mom is a bit scared of thunder ... then I say "not dangerous" (Johan at Crab).

\section{The Control Group}

One occasion

Conversations about the cat picture based on the same questions as that were used in the main group. Examples of four children's responses:

1. Don't think he is happy but I don't really know (Sara at Hedgehog).

2. The cat may be a bit lonely (Simon at Crab).

3. He's out for by himself. I'm not allowed to (Ida at Hedgehog).

4. Do you know her coat is white? I can see that (Ivar at Crab).

\section{Comments}

In this exercise the children in the main group shows that they have taken one step more between times 1 and time 2 in that they have thought and talked about the picture before suggesting a specific situation. The children show interest in the picture and all of them are involved. Their ideas and thoughts are "deep" and "genuine" in the sense that they experience the conversation and the issues as significant. In the control group the children's responses were not as development and can be main group`s responses on the first occasion.

\section{Dog Picture}

The second image is a dog picture. In the exercise the children are asked to think about the dog: How does it feel? What has it got round its neck? What happened? Does it hurt anyway else? How does it feel to be in pain? And do you feel sad then? The answer of four children in the main group, Björn, Stina, Sebastian and Rachel from the pre-schools Chaffinch and Lion and four children from the control group, Gunilla, Peter, Veronica and Carl are given below as representative of the responses to the questions. 


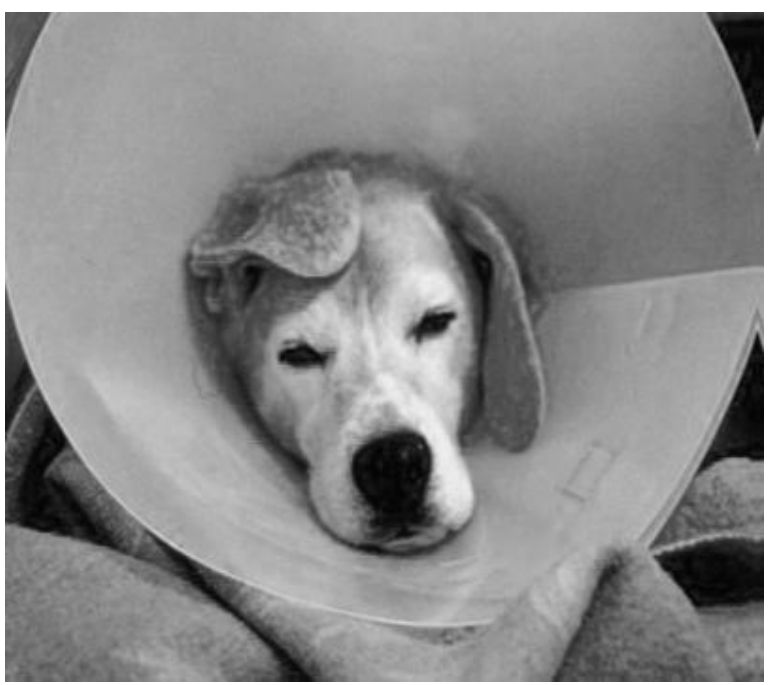

Figure 2: Sick dog. Illustrations by Kerstin Malm.

\section{The Main Group}

Occasion 1

Conversations about the dog picture on the issues raised by the questions above. Examples of the statements of the four children in the main group:

1. He hurts... in his ear I think ... He probably has a fever (Björn at Lion).

2. Is it a sick dog ... my dog is sick too ... in his leg ... in his paw ... He had a thing on his neck like that (Stina at Chaffinch).

3. I think he is sick in his throat ... he has a sore throat ... his whole neck and his ears. He is taking medicine (Sebastian at Lion).

4. Whatever he has hurting him... the poor thing (Rachel at Chaffinch).

Occasion 2

On this occasion a question comes up about the children have had earache at some point and continues with questions about they have had pain anywhere else. How does it feel to be in pain? And do you feel sad then? Below are the responses of the four children in the main group:

1. It hurts a lot ... know that it hurts ... I am sorry then ... If he has a bad ear. Had an ear ache ... got medicine and ointment ... dad bought it for me (Björn at Lion).

2. I hurt yesterday ... mom said I needed to rest ... got a sore throat but didn `t have anything like that on my neck. Poor doggy ... he needs to rest (Stina at Chaffinch).

3. I went to the doctor and showed my rash ... my throat itched ... it will be better now 
Agneta SIMEONSDOTTER SVENSSON. Preschool Children Development Empathy througt Individualized Materials

PROBLEMS

OF EDUCATION

IN THE $21^{\text {st }}$ CENTURY Volume 52, 2013

122

with the medicine dad said... it won 't it do so much... am not allowed to eat so many sweets it's a bit of a pity, get a little sad... I can give the dog something so his throat gets better. I feel sorry for him (Sebastian at Lion).

4. It's probably ... he has been bitten by a cat ... he has got that so it will get better again. Can get an injection.... I got an injection at the doctor. It hurt. Poor thing ... I know, we will give him some sweets and he'll get better (Rachel at Chaffinch).

\section{The Control Group}

One occasion

The conversation about the dog picture is based on the same questions as the main group. The responses of the four children:

1. The dog has a sore head. He has a clean hat on (Gunilla at Lion).

2. What has he done? It's probably sick... but I don't know (Peter at Chaffinch).

3. Oh dear, he is sick. Is he going to the hospital? (Veronica at Lion).

4. I know he is stuck in a fence (Carl at Chaffinch).

\section{Comments}

As before the conversations about the dog picture show a development in the children's understanding. Children learn that there are different perspectives and starting points that arouse their interest in ethical issues concerning animals. Talking to the children, questioning them and relating to how they perceive the image, reveals their genuine feelings and experiences. The child in the main group shows that their understanding increases both about the animal's and other people's needs. The responses of the children in the control group can be compared with those given by the children group on first occasion.

\section{Summary Comments}

The examples from the children in the main group (26 children) and the control group ( 26 children) representing all 52 children. Data from the 52 children gives a picture of how they develop empathy and understanding of animals and their living conditions. All the children in the main group worked with the exercises between the initial and final moment. The Hedgehog and the Crab attended 8 and 7 children from the main group and the Chaffinch and Leo, 6 and 5 children. Talks about animal pictures between the first and last time, was conducted and documented by preschool teachers. The examples have shown the children's thoughts about the animals and their living conditions.

\section{Discussion}

\section{The Main Group - Control Group}

The overall objective of the study is to investigate whether the understanding of animals and their living conditions is a way for child's emphatic ability. One interesting question chil- 
dren show children that they can develop empathy. Do children show any change in the way they talk about animals and their living conditions? What is that change?

An important aspect is that a difference emerges between the main group and the control group. All the children in the control group had to answer the same questions and talk about the same issues as the children in the main group did on the first occasion. The children in the main group had the opportunity to think reflect on and work with the material, on the first occasion, allowing their thoughts on ethical issues, to be stimulated and then re-developed in on the second occasion. The control group was given the opportunity to reflect on ethical issues, but they had not "practiced" on any previous occasion. According to Hoffman (2000) and Myyryb and Pesso (2010) working with and doing exercises based on images promotes empathy and it is important we stimulate empathy in children. The children in the control group had not developed the same answers or questions as those in the main group on the second occasion. The control group children responded with relatively few words and found it difficult to see the pictures in a wider context. The children in the main group expressed a greater understanding of ethical issues. The questions and statements became more developed from the first occasion of the second. The children showed that they could empathize with the animal's needs more significantly and also relate the animal's needs to people's needs. Above all, the vocabulary of the main group of children was more developed because they had the opportunity to express themselves based on their previous experience of a picture they could recognize and return to, the ability is empathize can be expressed in words, and in this way become a tool for thinking (Vygotskij, 1978).

Another method for investigating the topic could be a longitudinal study starting in kindergarten with a follow up in school. Such a study could provide additional knowledge about how children development their capacity for empathy through individualized exercises.

\section{Conclusions}

In conclusion, the study indicates that using teaching material picturing animals has an effect on the development of empathy among preschoolers. In general, it appears that there is a progression from training session 1 to session 2. The progress lies in the development of the children's ability to empathize when they are given opportunities to reflect on and re-evaluate earlier stances taken during the training time. There is no measurable difference between girls and boys, indicating job of the pre-school's teachers to work with children in order to reduce any differences that may arise later on in elementary school.

This study does not focus on "children in need of special support", with or without diagnoses but the illustrations and exercises could be important for "children in need of special support". They can learn to understand themselves by looking things from a different perspective. Their own resources can be developed and their own ability strengthened, which in turn strengthens the children's confidence.

As the present study shows that exercise develops young children's capacities for empathy, kindergartens and schools should work with ethical issues. From the perspective of the future, it pays to invest in children because they are the foundation of any future society. Practicing empathy develops ethics and morality and strengthens self-confidence in the children. Sustainable development must begin with the children. This is the best investment a society can make.

\section{Acknowledgment}

This study is supported by Animal Welfare Sweden. The author thanks Richard Ingemannsen for valuable technical support. 
Agneta SIMEONSDOTTER SVENSSON. Preschool Children Development Empathy througt Individualized Materials

PROBLEMS

OF EDUCATION

IN THE $21^{\text {st }}$ CENTURY

Volume 52,2013

\section{References}

Ascione, F. (2001). Animal Abuse and Youth Violence. Washington, DC: Department of Justice, Office of Justice Programs.

Dadds, M. R. (2002). Developmental Links between Cruelty to Animals and Human Violence. The Australian and New Zealand Journal of Criminology, 35 (3), 363-382.

Damon, W. (1984). Self-understanding and Moral Development from Childhood to Adolescence. In W. M. Kurtines, \& J. L. Gewirtz (Eds.), Morality, moral behaviour, and moral development (pp. 109127). New York: Wiley.

Gadamer, H. G. (1999). Hermeneutics, religion, and ethics. New Haven, CT: Yale University Press.

Gallie, W. B. (1956). Essentially contested concepts. Proceedings of the Aristotelian Society, 56 (1), 167198.

Hoffman, L. M. (2000). Empathy and Moral Development. Implications for Caring and Justice. New York: Cambridge University Press.

Juujarvi, S., Myyryb, L., \& Pesso, K. (2010). Does care reasoning make a difference? Relations between care, justice and dispositional empathy. Journal of Moral Education, 39 (4), 469-489.

Marton, F., Beaty, E., \& Dall'Alba, G. (1993). Conceptions of learning. International Journal of Educational Research, 19 (3), 277-300.

Marton, F., \& Pong, W. Y. (2005). On the unit of description in phenomenography. Higher Education Research \& Development, 24 (4), 335-348. doi: 10.1080/07294360500284706.

Melson, G. F. (2001). Why the wild things are: animals in the lives of children. London: Harvard University Press.

Mishler, E. G. (1986). Research Interview. Context and Narrative. London: Harvard University Press.

Myers, G. (1998). Children and animals: Social development and our connections to other species. Boulder, CO: Westview Press.

Poresky, R. H. (1990). The young children's empathy measure: reliability, validity and effects of companion animal bonding. Psychological Reports, 66 (3), 931-936. doi: 10.2466/pr0.1990.66.3.931.

Pramling Samuelsson, I., \& Johansson, E. (2006). Play and learning - inseparable dimensions in pre school practice. Early Child Development and Care, 176 (1), 47-65.

Pramling Samuelsson, I., \& Asplund Carlsson, M. (2008). The playing learning child: Towards pedagogy of early childhood. Scandinavian Journal of Educational Research, 52 (6), 623-641.

Pramling Samuelsson, I., Sommer, D., \& Hundeide, K. (In print). Early Childhood Care and Education A Child Perspective Paradigm. European Early Childhood Education Research Journal.

Simeonsdotter Svensson, A. (2009). Den pedagogiska samlingen i förskoleklassen - Barns olika sätt att erfara och hantera svårigheter (Göteborg Studies in Educational Sciences, 274). Göteborg: Acta Universitatis Gothoburgensis). Göteborg: Institutionen för pedagogik och didaktik.

Sommer, D., Pramling Samuelsson, I., \& Hundeide, K. (2010). Child Perspectives and Children's Perspectives in Theory and Practice. New York: Springer.

Vizek-Vidovic, V., Stetic, V. V., \& Bratko, D. (1999). Pet ownership, type of pet and socioemotional development of school children. Anthrozoos, 12 (4), 211-217.

Vygotskij, L. S. (1978). Mind of Society: The development of higher psychological processes. In V. Cole, S. John-Steiner, E. Scribner \& E. Sauberman (Eds.). Cambridge, Ma: Harvard University Press.

Advised by Ingrid Pramling Samuelsson, University of Gothenburg, Sweden

Received: January 31, $2013 \quad$ Accepted: March 20, 2013

Agneta Simeonsdotter Svensson
PhD., Lecturer, Department of Education, Communication and Learning, University of Gothenburg, Box 300, 40530 Gothenburg, Sweden.

Phone: +46 (0)31-7862045.

E-mail: Agneta.simeonsdotter@ped.gu.se 